\title{
Mobile Communications as a Challenges to the Mass Media
}

\section{Rusi Marinov}

Department of Mass Communication, New Bulgarian University, ul. "Montevideo" 21, 1618 Sofia, Bulgaria

\begin{abstract}
In this article we discuss the role of mobile communications in the business and media and howthe mobile computing, tools and applications change the world and behaviour of the people.Based on a series of analysis and observation show some tendencies for development ofmobile technology Internet role of the media in these processes.
\end{abstract}

\author{
Publication History: \\ Received: August 14, 2015 \\ Accepted: December 22, 2015 \\ Published: December 24, 2015
}

\section{Keywords:}

Mobile applications, Apps, Media computing, New media, Internet, Networking, Smartphones
In the last two three years the mobile technologiesstart to play a dominant role in communication among people. According to international statistics ${ }^{1}$ for the development of mobile forms of communications in 2012 noticed the following major trends: number of users worldwide is 5.9 billion, i.e. covering $87 \%$ of the entire population of Earth. 1.2 billion. Many persons are subscribers of mobile network services as leading countries with thehighest share of broadband connectivity are South Korea and Japan, coated respectively $91 \%$ and $88 \%$. Global mobile communication network is oriented towards the use of special software programs / apps /, which specifically handle data and provide content and entertainment users. This trend has even outpaced the popularity of social networks, they exist for the accelerated purchaseor bring applications from external developers. Official statistics shows that currently available on the market more one million mobile apps and 10 billion. Times are downloaded to mobile devices. In 2013 it is expected boom of these technologies and applications. The most commonly used applications in the gaming, news, maps, music, social networking and books / see. Scheme /.



Global mobile communication network is oriented towards the use of special software programs / apps /, which specifically provide and process information and entertainment content to its users. This trend has even outpaced the popularity ofsocial networks and the last to exist accelerated purchase or bring your own pages applications from external developers.

As an example can be mentioned the most expensive in the world now use Instagram, bought by Facebook for the sum of $\$ 1$ billion.

According to "Wikipedia" applications in the Google Play store in 2011, numbering 500,000. Android platform with more than 10 billion

${ }^{1}$ http://mobithinking.com/mobile-marketing-tools/latest-mobile-stats installation on mobile devices. Specifically for tablets based on Android, there are several thousands of apps in 20 categories: entertainment and games-6158;e-books-2289;leisure-2080;resources and public services-1552;education-1327; lifestyle-1013 ;communications713;products-681; health and fitness 537; music-517; travel-402; religions-268; home-130; locations and maps-121; social networks 112. The number of applications for Apple is even greater and for iPad, in 2011 reached 90,000 programs and for iPhone-475,000 apps Accordingly, applications for Blackberry are 18000 and Nokia 130 000 .

I will give some popular dfinition about mobile communication. In the Wikipedia ${ }^{2}$ mobile computing is defined as human-computer interaction by which a computer is expected to be transported during normal usage. Mobile computing involves mobile communication, mobile hardware, and mobile software. Communication issues include ad hoc and infrastructure networks as well as communication properties, protocols, data formats and concrete technologies. Hardware includes mobile devices or device components. Mobile software deals with the characteristics and requirements of mobile applications.Wiki answers ${ }^{3}$ pointed aboutmobile communication: a communication network (either public or private) which doesn't depend on any physical connection between two communication entities and have flexibility to be mobile during communication.

A Mobile Internet Device (MID) ${ }^{4}$ is a small multimedia-enabled mobile device that provides wireless Internet access. MIDs facilitate real-time and two-way communication by filling the multimedia gap between mobile phones and tablets. MID technology focuses on providing entertainment, information and location-based services to individual consumers, rather than enterprises. Webopedia ${ }^{5}$ notes that mobile devices are multi-functional devices capable of hosting

${ }^{2} \mathrm{http}: / /$ en.wikipedia.org/wiki/Mobile_computing

${ }^{3}$ http://wiki.answers.com/Q/Definition_of_mobile_communication ${ }^{4} \mathrm{http}: / /$ www.techopedia.com/definition/24207/mobile-internet-device-mid ${ }^{5}$ http://www.webopedia.com/quick_ref/mobile_OS.asp

*Corresponding Author: Dr. Rusi Marinov, Department of Mass Communication, New Bulgarian University, ul. "Montevideo" 21, 1618 Sofia, Bulgaria, E-mail: rmarinov@nbu.bg

Citation: Marinov R (2015) Mobile Communications as a Challenges to the Mass Media. Int J Journalism Mass Comm 2: 113. doi: https://doi.org/10.15344/23492635/2015/113

Copyright: ( 2015 Marinov. This is an open-access article distributed under the terms of the Creative Commons Attribution License, which permits unrestricted use, distribution, and reproduction in any medium, provided the original author and source are credited. 
a broad range of applications for both business and consumer use. Smart phones and tablets allow people to access the Internet for email, instant messaging, text messaging and Web browsing, as well as work documents, contact lists and more. The mobile devices are often seen as an extension to your own PC. Work done on the road, or away from the office can be synchronized with your PC to reflect changes and new information. Mobile Operating Systems (Mobile OS)-like a computer operating system, a mobile operating systemis the software platform on top of which other programs run. The operating system is responsible for determining the functions and features available on your device, such as thumbwheel, keyboards, WAP, synchronization with applications, e-mail, text messaging and more. The mobile operating system will also determine which third-party applications can be used on your device. Some of the more common and wellknown Mobile operating systems include the following:

Symbian OS- has become a standard operating system for smartphones, and is licensed by more than 85 percent of the world's handset manufacturers. The Symbian OS is designed for the specific requirements of $2.5 \mathrm{G}$ and $3 \mathrm{G}$ mobile phones.Windows Mobileplatform is available on a variety of devices from a variety of wireless operators. You will find Windows Mobile software on Dell, HP, Motorola, Palm and i-mate products. Palm OS- since the introduction of the first Palm Pilot in 1996, the Palm OS platform has provided mobile devices with essential business tools, as well as capability to access the Internet or a central corporate database via a wireless connection.Mobile Linux-m the first company to launch phones with Linux as its OS was Motorola in 2003. Linux is seen as a suitable option for higher-end phones with powerful processors and larger amounts of memory. MXI -is a universal mobile operating system that allows existing full-fledged desktop and mobile applications written for Windows, Linux, Java, Palm be enabled immediately on mobile devices without any redevelopment. MXI allows for interoperability between various platforms, networks, software and hardware components.

According to comScore [1], for the three months ending April 2013, 58 percent of cellphones in the U.S. were smartphones. Of course that's the U.S. market, and the U.S. is the third largest cellphone market in the world with 327.5 million devices. That's a rather paltry number compared to China's 1.15 billion and India's 867.8 million. The vast majority of those devices arebasic voice or feature phones, but it won't stay that way for long. The biggest growth market for smartphones will be in those developing markets.

Further driving that prediction is the fact that the smartphone will likely be the primary Internet access device for users in those developing countries. While Internet penetration in developed countries is hovering around 80 percent to 90 percent of the population today, it's 42.3 percent in China and 12.6 percent in India. By the way, the mobile phone penetration in those countries is 85.2 percent and 70.7 percent, respectively.There has been talk of Apple coming out with a low cost iPhone for those developing markets, but with Apple's cost structure I find it hard to believe they could succeed in a price war with the likes of Samsung, HTC, ZTE, and Huawei. While Apple's offering might be "low cost" in U.S. terms, it would still be a premium product in those developing countries. As the smartphone markets in those developing countries begins to take shape, Android's share of the smartphone market, which is already three times Apple's worldwide share, will simply explode. As things stand I don't see either Windows Phone or BlackBerry getting much of the action.
In 2012 comScore presented a number of apps [2] in the world:

Apple app store-850 000;

Amazon appstore-75 000;

BlackBerry -120 000;

Google play-800 000;

Nokia Store-116 000;

Samsung apps-13 000;

After two years or in 2013 the number of apps are become:

Apple apps-850 000;

Windows phone store-145 000;

Canalys/apps avaible on Google play and Apple-800 000;

Most popular type of apps are: games-33\%; widgets-8\%; entertainment-7\%;music- $4 \%$. Gartner.com predicted that downloads of mibile apps from all stores are: in 2014-119 billion; 2015- 189 billion; 2018- 287 billion.Acording to the one research providing by Pew [3] reserach center in 2014,the world is moving rapidly towards ubiquitous connectivity that will further change how and where people associate,gather and share information, and consume media. In this research took part about 2,558 experts and technology builders about where we will stand by the year 2025 finds striking patterns in their predictions. They registered their answers online between November 25, 2013, and January 13, 2014. the experts agree on the technology change that lies ahead, even as they disagree about its ramifications. Most believe there will be:

- a global, immersive, invisible, ambient networked computing environment built through the continued proliferation of smart sensors,cameras, software, databases, and massive data centers in a world-spanning information fabric known as the Internet of Things;

- "augmented reality" enhancements to the real-world input that people perceive through the use of portable/wearable/implantable technologies.

- disruption of business models established in the 20th century (most notably impacting finance, entertainment, publishers of all sorts, and education);

- tagging, databasing, and intelligent analytical mapping of the physical and social realms.

The global telecoms market [4] landscape has changed remarkably in the last few years. There are far more mobile broadband subscribers worldwide today than the number of fixed broadband subscribers and Asia has the most mobile broadband connections. Fixed Internet users continues to grow with around 2.9 billion forecast for 2014; Mobile subscriptions are expected to surpass the global population by the end of 2014 and AT\&T, NTT and Verizon are some of the top carriers worldwide in terms of sales.Some examples of key insights in the scope of mobile market communications [5]: Mobile subscriptions (including multiple subscriptions) are expected to reach around 6.9 billion in 2013 - with the market share of consumers using smart phones to also reach around $18 \%$, the equivalent of around 1.3 billion users. There is still much potential growth ahead for smart phone uptake. Despite its phenomenal growth - which will continue for many years to come - the smartphone is set to eventually become a utility product. The difference between the fixed and the mobile network will become increasingly blurred, with mobile handsets simply being devices wirelessly connected to the fixed network. These developments will stimulate Fixed-Mobile Conversion (FMC). Regulatory interventions are driving the continuing decline of Mobile Termination Rates (MTR) around the world, which have been in 
decline since at least 2005. It is expected that 2013 and 2014 will see a positive growth in mobile infrastructure spend as carriers are forced to upgrade and deploy new networks to cope with demand. By 2017 around $45 \%$ of mobile traffic is expected to be offloaded from Wi-Fi or fixed.The top mobile operator worldwide in terms of connections is China Mobile, followed by Vodafone Group.

The costs of acquiring a customer have grown along with the increase in smart phone uptake. Subsidising handsets is an expensive exercise and it is has become even more important for the telcos to retain the customer once they are on board.Roughly $80 \%$ of Latin America and the Caribbean's (LAC) mobile market is served by five multinational operators: América Móvil, Telefónica, Telecom Italia, Millicom, and Digicel. América Móvil is the leader, followed by Telefónica. Between them, these two operators serve $61 \%$ of the region's mobile subscribers.Smartphone adoption rising sharply in Africa.In Australia smart device penetration exceeds $90 \%$ for GenY users.Mobile markets in Asia continued to experience strong growth during 2012 and into 2013, despite many countries in the region having subscriber penetrations of over $150 \%$.Sage publicattion [6] pointed out that mobile communication as an innovation, including the emergence of new usage forms, the negotiation of norms, and symbolic representation by producers and users. The interrelationship of this nearly ubiquitous technology and the users' everyday lives. To this moment,there are 2.1 billion mobile Web users in the world [7]. According to estimates by The ITU (June, 2013), there are 2.1 billion active mobile-broadband subscriptions in the world (this is people with a $3 \mathrm{G}$ or $4 \mathrm{G}$ connection). That is 29.5 percent of the global population and below are some interesting facts:

- Mobile-broadband subscriptions have grown 40 percent annually over the last three years.

- Mobile-broadband subscription outnumber fixed broadband subscriptions 3:1.

- In developed countries mobile-broadband users often also have access to a fixed-broadband connection, but in developing

countries mobile broadband is often the only access method available to people.

- Informa believes there were 1.9 billion $3 \mathrm{G}$ and $4 \mathrm{G}$ subscribers at the end of Q2 2013. See below for a breakdown of 3G/4Gby country and definitions of $3 \mathrm{G} / 4 \mathrm{G}$.

- Ericsson (June 2013) estimates that there were 1.7 billion global mobile broadband subscriptions at the end of Q1 2013.

This is forecast to reach 7 billion in 2018. The mobile phone (smartphone) will continue to be the dominant mobile broadband access device.Top countries for mobile broadband4G: USA is leading the world with 62.5 million subscribers to $4 \mathrm{G}$ networks, followed by Japan and South Korea. By market penetration the leaders are South Korea, Singapore and Japan, according to Informa (Q2 2013).3G: China has the most $3 \mathrm{G}$ subscribers at 325.5 million, ahead of the USA and Japan. By market penetration the leaders are Italy, Japan and UK, according to Informa (Q2 2013). A 4G or fourth-generation network generally refers to an a high-speed mobile network based on LTE (Long Term Evolution). 4G networks deliver data, such as Web pages, emails, music or video, much faster than $3 \mathrm{G}$ or UMTS (Universal Mobile Telecommunications System) networks, which in turn were much faster than 2 G GSM networks.
Charting the growth of the App Store [8] since its launch in July 2008 is to watch a market explode. In just a few short years, the App Store has transformed how interact with mobile devices and built many successful businesses. Below is a list of the total number of apps available in the App Store at given dates in the past.The list is based on Apple announcements and numbers are approximate:

June $2014-1,200,000$

October 2013 - 1,000,000 (475,000 native to iPad)

June 2013 - 900,000 (375,000 native to iPad)

Jan. 2013 - 775,000 (300,000 native to iPad)

Sept. 2012 - 700,000 (250,000 native to iPad)

June 2012 - 650,000 (225,000 native to iPad)

April 2012 - 600,000 (200,000 native to iPad

Current number of Android [9] apps in the market:1,319,987. Percentage of low quality apps: $17 \%$ development over time. ABI Research [10] estimated mobile users will download 70 billion apps in 2013 - 58 billion to smartphones and 14 billion to tablets. As one put it, that's over 10 apps downloaded per human being on Earth. Given the sheer pace of change in the mobile market today, you may be wondering - just how many apps are there now in each of the major app stores? And how do these counts compare with one another? Well, wonder no more.Here's our updated inventory of apps available on Android, iOS, Windows, and Blackberry (some are official, some are estimates as reported):Google Play/Android is estimated to have 800,000 apps (Jan. 4, 2013). Apple iOS App Store recently reported 775,000 apps (Jan. 7, 2013). Windows Phone Marketplace is up to 125,000 apps (Oct. 25, 2012). Blackberry World is now up to 70,000 apps (Jan. 30, 2013).

Microsoft claims Windows Store has 400,000 apps, saw its 5 billionth download in March [11] Microsoft hasn't quite managed to close the app gap between its own app stores and the behemoths that are iOS and Android, but the company has made significant progress over the past several months. Neowin came across the sign you see in the image above at the Microsoft Build Developer Conference on Wednesday, proclaiming the latest milestone ofthe Windows app stores: 400,000 apps between PCs and mobile devices.The Windows app store has accumulated over 150,000 apps according to MetroScanner, which means that theWindows Phone store has topped 250,000, almost doubling the amount of apps on the store around the same time last year. Additionally, Windows users are now downloading 14 million apps a day between their various devices. Expect plenty more news when Microsoft takes the stage at the Build Developer Conference.

Media apps [12]- these are free app and only includes 24 hours News TV Live through selected English broadcasters.

On Air:

*Aljazeera from Qatar

${ }^{\star}$ Arirang TV from Korea

${ }^{\star} \mathrm{BBC}$ World from UK

${ }^{\star}$ CCTV from China

${ }^{\star}$ Channel News Asia from Singapore

${ }^{\star} \mathrm{CNN}$ from USA

${ }^{\star}$ eNCA from South Africa

* euro news from France

${ }^{*}$ FRANCE24 from France

${ }^{\star}$ NHK World from Japan

${ }^{\star}$ NDTV from India

${ }^{\star}$ PRESS TV from Iran

${ }^{*} \mathrm{RT}$ (Russia Today) from Russia 


\section{${ }^{*}$ RTÉ NEWS NOW from Ireland \\ ${ }^{\star}$ SKY NEWS from UK}

These great broadcasters from each country let you know the high quality international Headline News, Breaking News, Exclusive, Business, Sports, Documentary, Debate, Weather forecast and more.

A new infographic titled "Global Mobile Apps Statistics" [13] shows us just how many apps are out there, and how many people are consuming them.The Apple App Store leads in the number of apps available, with an impressive 850,000 apps, followed by the Google Play Store which clocks in with over 800,000 apps for the Android platform. The Microsoft Windows Phone Store comes in third with 145,000 apps available, and BlackBerry's App World taking up the rear with 120,000 apps available.Direct revenue from app sales in 2011 is estimated at around $\$ 7.3$ Billion, and expected to reach $\$ 36.7$ Billion by the year 2015. With the continued popularity of tablets and the proliferation of more affordable smartphones to emerging markets, it is clear that apps arehere to stay.

Some Black Berry apps [14] in the area of news are/se the pictures/.

Global Mobile applications in the world 2014 [15] shows a forecast for the number of mobile app downloads from 2009 to 2017. In 2009, worldwide mobile app downloads amounted to approximately 2.52 billion and are expected to reach 268.69 billion in 2017. In 2010, earnings of mobile apps providers amounted to 6.8 billion U.S. dollars.
Number of mobile apps downloads worldwide

102,062 million;

Forecasted number of apps downloads 2017

$268,692 \mathrm{~m}$

Number of free mobile apps downloads

92.88 billion;

Number of paid mobile app downloads

9.19 bn.

Worldwide mobile app revenue26.68 bn US\$.

App Stores Values Statistic-number of apps available in Google Play store 1,000,000. Number of apps available in Windows Phone store

160,000. Number of monthly downloads from Apple App Store-75 billion. Number of unique U.S. visitors to Apple iTunes app on iOS32.64 million; number of unique U.S. visitors to Android Market app on Android $49.72 \mathrm{~m}$.

I give further some details about mobile applications using by global news agency and media. Reuters News Pro Applications [16] -Reuters mobile applications provide user with access to professional-grade news and market data wherever and whenever you want it. Application features include:extensive world, business and market news; global financial data; corporate information; personalized stock tab; the latest sports, science, health, technology and entertainment news; fast on or offline access to the latest breaking news; full story articles and

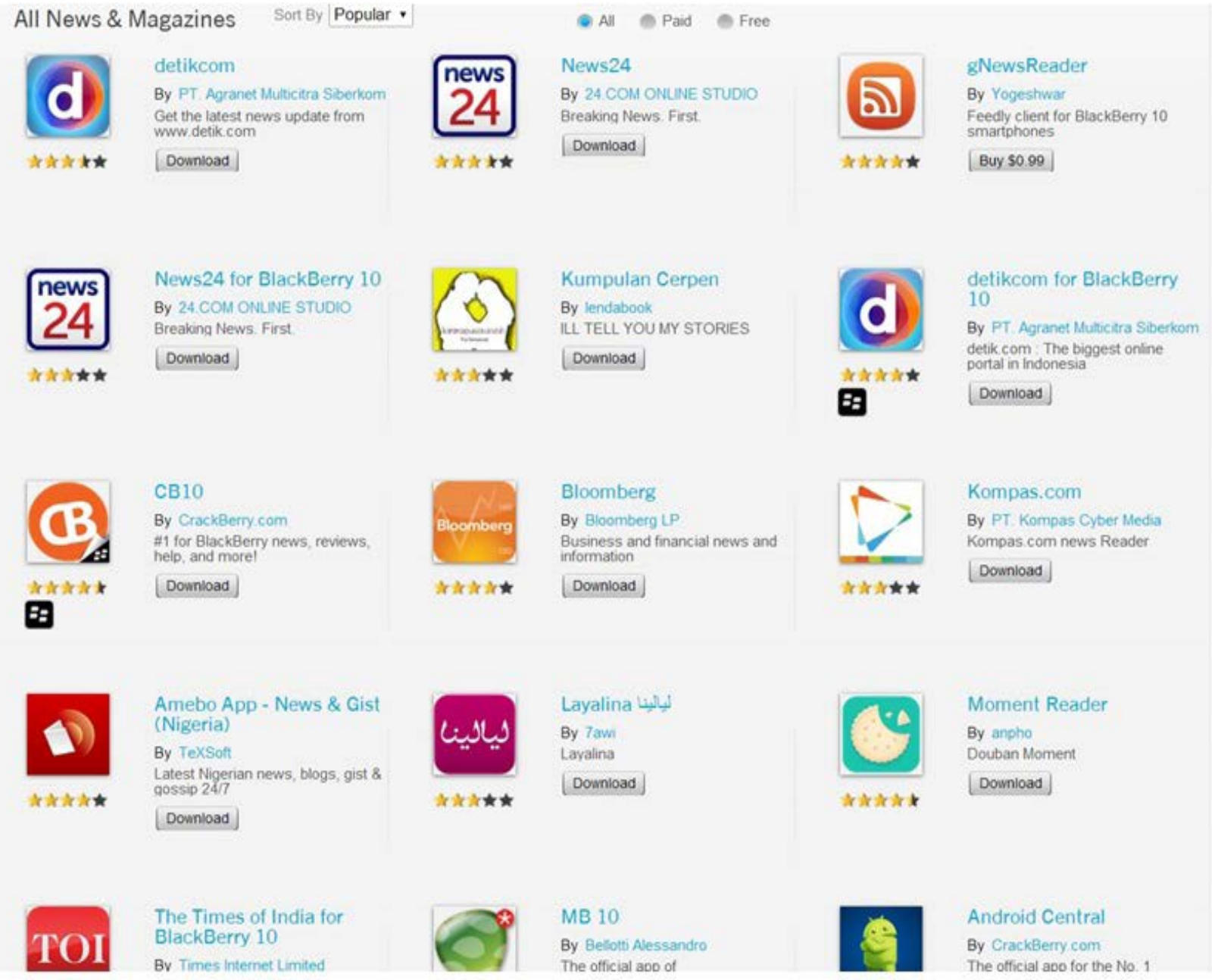


photos optimized for easy reading on your mobile device. Reuters News Pro for iPad-Optimized interactive charting and financial data manipulation that takes advantage of the unique attributes of the iPad platform. Video and pictures load quickly and play in high quality, enabling rapid viewing of our multimedia offerings. Horizontal scroll and split-screen reading capabilities provide access to the full breadth of our content from virtually any part of the application, saving time with efficient browsing and quick search features throughout. Ability to change time-series on a financial chart with a simple pinch gesture. Caching mechanism that enables off-line reading.

In the Apple "itunes" there are information about Reuters News Pro for $\mathrm{iPad}^{6}$. Some description of apps: access professional-grade news and market data from Thomson Reuters, the world's leading source for intelligent information for businesses and professionals. Thomson Reuters News Pro for iPad gives you knowledge to act, with fast on or offline access to the latest breaking news, pictures and video, together with extensive global.

Category: News.Updated: Dec 02, 2013.Version: 2.9.1. Size: 12.1 MB. Languages: English, Simplified Chinese.

\section{In the Google play ${ }^{7}$ there are 7 apps for Reuters}

- Thomson Reuters - August 7, 2014. Category: News \& Magazines. Description: Reuters app delivers breaking news, analysis and market data from the world's most trusted news organization. Explore a seamless stream of articles, pictures, and videos on your phone or tablet.Features include:breadth of Coverage: Navigate between stories to explore a wide range of topics from Politics to Opinion to Oddly Enough and more; customization: Create and edit your personal watchlist of tickers; flexible Access: Read online or save stories and read them later offline.

- Thomson Reuters Eikon - the most comprehensive, intuitive, and collaborative set of financial tools available.

- Thomson Reuters ProView is a professional grade platform that allows you to interact with your eBooks in entirely new ways.

- $\quad$ Reuters Sports Reel - July 17, 2014

- Thomson Reuters Convene - July 17, 2014. Business- Travel light and travel smoothly when you attend Thomson Reuters conferences, seminars, and other events

- Thomson Reuters Exchange- February 25, 2014. From the financial and risk experts at Thomson Reuters, the Exchange Magazine app delivers insight, ideas, news, and information to help financial professionals drive profitability, connect, collaborate, and manage risk.Each issue includes interviews with and articles by financial industry executives and experts about the latest trends, strategies, and developments. You'll also find data graphics, research studies, and more.

The euronews ${ }^{8}$ app offers 5 applications available on the App store; Google play; Blackberry world; Nokia. Euronews Express offers the latest news stories with text and pictures from Europe's most watched news channel. The app is designed for best performance even on poor quality mobile networks and allows offline reading. Euronews covers international news in 13 languages. With 400 journalists from more than 30 nationalities. Euronews offers a unique, independent and

${ }^{6}$ https://play.google.com/store/apps/details?id=com.thomsonreuters.reuters ${ }^{7}$ www.euronews.com. http://store.ovi.com/content/440206

${ }^{8} \mathrm{http} / / /$ www.bbc.com/news/10628994 totally impartial perspectiveon world events.Sections of the news:current affairs, business, culture and science news in video, reports and magazines in VOD, live streaming of euronews TV, express your opinion. The euronews EXPRESS app offers- the latest news stories, best performance even on poor quality mobile networks; offline reading possibility, notifications for breaking news (on iOS and Android); visualize other users 'opinions' on an interactive map; share articles via social networks, search stories easily; receive alerts for breaking news (only on iOS). The euronews app is available in 13 editions: English, Arabic, French, German, Greek, Hungarian, Italian, Persian, Portuguese, Russian, Spanish, Turkish.

The BBC News appis now available for Android smartphones and tablets, as well as for iPhone, iPad and iPod Touch. The app is free to download. Go to Google Play or the Apple app store to download the official BBC News app. Get the latest and breaking news from the BBC and our global network of journalists. Stories are arranged in categories including top stories, UK, world, politics, business, technology, health, entertainment \& arts and sport. The app offers stories and video, and you can personalise the homescreen by adding and removing news categories to suit your interests. They have developed a series of launcher apps for Blackberry phones to give you quick access to BBC News on Blackberry smartphones 5 and above. As some BlackBerry connections are routed overseas, BlackBerry users occasionally have problems accessing $\mathrm{BBC}$ content that is only available inside the UK. The application will also help to stop this from happening and make sure that, if you're in the UK, you can access everything that you ought to be able to access. BBC news in Google play. Apps-more than 40 applications for android. BBC in Apple store-12 apps.

New York Times appsfor iPhone iPad-6 apps; for Andoroid-1; Windows phone -1; BlackBerry-1; Kindle fire-1; Windows 8-1; iPad2. NYT Opinion ${ }^{11}$ - read columnists, editorials, letters to the editor, articles and Daily news commentary. Category: News. Updated: Aug 04, 2014. Version: 1.0.3. Size: 9.2 MB. Languages: English, Bokmål, Norwegian, Czech, Danish, Dutch, French, German, Italian, Japanese, Korean, Russian, Simplified Chinese, Slovak, Spanish, Swedish, Traditional Chinese, Vietnamese.

\section{More iPhone Apps by The New York Times company:}

\section{- $\quad$ NYTimes - Breaking National \& World News \\ - The New York Times Crossword \\ - View In iTunes \\ - $\quad$ NYT Now \\ - NYTimes Real Estate}

In topsy.com there are about 4074 results connected to "mobile communications"in the last 30 days.Video clips aboit 63/last 30 days.If we serach information in YouTube we would find 320000 results and vidoe clips about"mobile communications'. Amazon_books about Mobile communications: 77,043 results for "Mobile communications", and 110 results for "Mobile communications and mass media". In Books google- we have about 376,000 results ( 0.88 seconds). Mobile computing technologies such as wireless access points, laptops tabletPC's, PDA's, cell phones, Bluetooth enabled devices, and fusion

${ }^{9}$ https://play.google.com/store/search?q=bbc\%20news\%20app\&hl=en ${ }^{10} \mathrm{http}: / /$ www.nytimes.com/services/mobile/index.html? action $=\mathrm{cl}$ ick \&pgtype $=$ Homepage $\&$ region $=$ SiteIndex $\&$ module $=$ SiteIndex $\&$ contentCollection $=$ Mobile $\% 20$ Applications \&WT.nav=footer - nav ${ }^{11} \mathrm{https} / /$ itunes.apple.com/us/app/id868810767? $\mathrm{mt}=8$ 
Citation: Marinov R (2015) Mobile Communications as a Challenges to the Mass Media. Int J Journalism Mass Comm 2: 113. doi: https://doi.org/10.15344/23492635/2015/113

devices are those devices that have the capabilities to offer learning experiences that can effectively engage and educate contemporary learners in a variety of new ways not typicallyallowed by conventional desktop computers.

According to comScore in June 2014 [17], this is the first time mobile apps have accounted for more than $50 \%$ of all digital media consumption. As far as content goes, mobile users tend to use radio and photo applications the most, followed by mapping and instant messaging applications, and of course, games.

\section{Conclusion}

Mobile forms of communication is rapidly becoming most powerful tools of business, and user demand for more useful applications is the various spheres. Additionally, this article shows how these mobile compuitng tools change the media landscape in the world.

\section{Competing Interests}

The author declare he has no competing interests exists.

\section{References}

1. The Mobile Revolution is Just Getting Started.

2. http://techcrunch.com/2012/07/02/comscore-in-u-s-mobile-marketsamsung-android-top-the-charts-apps-overtake-web-browsing

3. Theses About the Digital Future. Digital Life in 2025: Hear is original sources.

4. Global Telecoms - The Big Picture - Key Industry Statistics.

5. http://www.budde.com.au/Research/2013-Global-MobileCommunications-Statistics-Trends-and-Regional-Insights.html

6. Mobile Media \& Communication

7. Mobilebroadband.

8. Sam Costello. How Many Apps Are in the iPhone App Store?

9. http://www.appbrain.com/stats/number-of-android-apps

10. How Many Apps Are in Each App Store?

11. http://mobilesyrup.com/2014/04/07/microsoft-claims-windows-store-has400000-apps-saw-its-5-billionth-download-in-march/ by Jacob Siegal on Apr 2, 2014. http://bgr.com/2014/04/02/windows-windows-phone-appstores-400000-apps/

12. What's happening across the Globe with the Breaking News on the world?

13. http://www.intomobile.com/2013/05/31/mobile-apps-have-changed-worldinfographic/

14. News \& Magazines Categories.

15. http://www.statista.com/statistics/266488/forecast-of-mobile-app downloads/

16. http://www.reuters.com/tools/mobile

17. http://www.businessinsider.com/chart-of-the-day-mobile-apps-dominatingmedia-consumption-2014-6\#ixzz3AD7ysH5Y 